\title{
Pathogenicity of Leptosphaeria maculans Isolates on a Brassica napus-B. juncea Recombinant Line
}

\author{
Irénée Somda, Régine Delourme, Michel Renard, and Hortense Brun
}

First and fourth authors: Station de Pathologie Végétale, INRA, BP 29, F-35653 Le Rheu Cedex, France; and second and third authors: Station d'Amélioration des Plantes, INRA, BP 29, F-35653 Le Rheu Cedex, France.

Current address of I. Somda: IDR/UPB, BP 1091, Bobo-Dioulasso, Burkina Faso.

Accepted for publication 28 October 1998.

\section{ABSTRACT}

Somda, I., Delourme, R., Renard, M., and Brun, H. 1999. Pathogenicity of Leptosphaeria maculans isolates on a Brassica napus-B. juncea recombinant line. Phytopathology 89:169-175.

The Brassica napus-B. juncea recombinant line (MX), resistant to Leptosphaeria maculans, was produced by interspecific crosses and bears one gene (Jlml) from the B. juncea B genome. We investigated whether this new resistance was race specific by characterizing protection against a large sample of $L$. maculans isolates. The pathogenicity of 119 isolates of L. maculans comprising 105 A-group isolates and 14 B-group isolates was studied at the cotyledon stage under controlled conditions using the MX line, the susceptible B. napus cultivar Westar, and the resistant $B$. juncea cultivar Picra. All but one of the isolates were pathogenic on 'Westar'. Only 3 of the 105 A-group isolates caused very mild symptoms on 'Picra'.
Two of these strains were isolated from the MX line and the other from Sinapis arvensis. The other 102 strains caused hypersensitive-type responses. Most B-group isolates were pathogenic on 'Picra'. There were differences in pathogenicity among A-group isolates tested on the MX line, whereas all B-group isolates were pathogenic on this line. A-group isolates obtained from the MX line were more frequently pathogenic on the MX line than those obtained from B. napus cultivars. One isolate from $S$. arvensis infected the MX line. These results suggest that the resistance of the MX line is unlikely to be durable. Thus, the new resistance gene JlmI should probably be used in association with other sources of resistance, in plant breeding schemes, to prevent the breakdown of this resistance.

Additional keywords: blackleg, host-pathogen interactions, Phoma lingam.
Most of the Brassica napus L. var. oleifera (oilseed rape) cultivars currently grown in France are highly susceptible at the seedling stage and moderately susceptible at the adult plant stage to Leptosphaeria maculans (Desmaz.) Ces. \& De Not. (anamorph: Phoma lingam (Tode ex Fr.) Desmaz.), the causal agent of blackleg. Yield losses due to blackleg have been large in Australia (35, $37)$, Canada $(28,29)$, and some European countries such as France (32), England (12), and Germany (39). Populations of L. maculans have been classified into two genetically distinct groups (A and B groups) on the basis of pathogenicity $(8,17)$, isozyme banding patterns $(3,5,14,42)$, and molecular markers $(16,18,45)$. A-group isolates (also called highly virulent, aggressive, or Tox+) and B-group isolates (also called weakly virulent, nonaggressive, or Tox0) are not interfertile $(4,41)$ and may be considered to be different species $(13,22,23)$. A-group isolates are responsible for severe stem canker in oilseed rape, whereas B-group isolates mainly cause pith damage (17). The pathogenicity of L. maculans differs between Brassica species (31). Mustards with the B genome, including $B$. juncea (L.) Czernj. \& Coss., are totally resistant to A-group isolates. This resistance is generally manifested as a hypersensitive reaction (HR)-type response $(36,42)$. In contrast, $B$. juncea is susceptible to B-group isolates used to inoculate cotyledons and stems $(11,17,42)$.

The resistance of $B$. juncea to A-group isolates depends on two or three genes $(15,24,30,44)$. B. juncea is currently used in many breeding programs to improve the resistance of $B$. napus cultivars at all growth stages $(24,30,34)$. B. napus- $B$. juncea recombinant lines containing a single resistance gene (Jlml) from $B$. juncea have

Corresponding author: H. Brun; E-mail address: brun@rennes.inra.fr

Publication no. P-1998-1222-02R

(C) 1999 The American Phytopathological Society been obtained (6). They are highly resistant under heavy disease pressure in field trials and may become commercially available in the near future.

Monogenic resistance has proved to be ephemeral in a number of crops (25), so it is of great value to test whether there are virulent isolates of L. maculans that can overcome the Jlml resistance gene. The potential durability of the resistance conferred by this gene is unknown. Its resistance spectrum was assessed by investigating differences in the pathogenicity of $L$. maculans populations in the presence of this new source of resistance in B. napus.

L. maculans isolates were recovered from various cultivated and wild cruciferous hosts, particularly from plants of the B. napus-B. juncea recombinant line MX that had mild symptoms. We investigated, under controlled conditions, the pathogenicity of these isolates on the MX line and parental species, B. napus and B. juncea, at the cotyledon stage. We report that the resistance to $L$. maculans conferred to B. napus by a single gene (Jlml) from the $B$. juncea $\mathrm{B}$ genome was race specific.

\section{MATERIALS AND METHODS}

Plant material. The pathogenicity of the isolates was analyzed using three Brassica genotypes: the B. napus-B. juncea recombinant line MX, the $B$. napus cultivar Westar and the $B$. juncea cultivar Picra. The MX line was selected from interspecific hybrid material obtained in Australia by Roy (33). This recombinant line was selected for normal meiotic behavior $(2 \mathrm{n}=38)$, stability, and homogeneous blackleg resistance at the cotyledon stage at the Plant Breeding Station, INRA-Rennes, France (6). Segregation ratios were analyzed in various progenies, and resistance was found to be monogenic (6). The actual $B$. juncea resistance donor (BJ168) and B. napus recipient germ plasm ("Cresus-o-Precose") were not available, so the resistant $B$. juncea 'Picra' and the highly susceptible B. napus 'Westar' were used as controls in place of the 
actual parents. The MX line and 'Picra' both carry the $B$. juncea resistance gene $(\mathrm{Jlml})$, because they both have the three specific random amplified polymorphic DNA (RAPD) markers tightly linked to the Jlm 1 resistance gene in the MX line (6).

Isolates of $\mathbf{L}$. maculans. We studied 119 isolates of $L$. maculans (Table 1). Single ascospore isolates were obtained from pseudothecia on stem base residues and pycnidiospore-mass isolates were obtained from damaged tissues of various oilseed rape genotypes and the MX line as described by Somda et al. (42). Isolates were classified as A- or B-group isolates according to glucose phosphate isomerase patterns (40). Most of the isolates studied were collected in 1992, 1993, and 1994 from heavily diseased field trials. The infected B. napus plant stem residues used as a source of inoculum in the trials originated from various growing areas in France. Under these conditions, the frequency of leaf lesions and stem cankers was much lower on the MX line than on susceptible oilseed rape cultivars during the growing season (6). Nevertheless, a few pseudothecia were recovered in the autumn from stem base residues of the MX line. Single ascospore isolates were produced from these pseudothecia.

Twenty-five single-ascospore isolates of L. maculans (R1 to R25) were obtained from the MX line in 1992. Forty single-ascospore isolates (termed MX) from the MX line and nineteen single-ascospore isolates (termed Co) from oilseed rape cultivars were collected from stem residues in a single field experiment in 1993. Six pycnidiospore-mass isolates were recovered in 1993 and 1994 from rare lesions that developed on the leaves (MX-L), stem (MX-S), collar (MX-C), and pods (MX-P) of the MX line. Twenty-two isolates were collected from $B$. napus in diverse geographic regions (France, United Kingdom, Canada, Poland, and Germany). We also studied seven isolates from leaf lesions on Raphanus sativus (radish), Eruca sativa, Sinapis arvensis (wild mustard), and the synthetic Raphanobrassica McNaughton (RBMN) (20).

Cotyledon inoculations. Seeds of each genotype were sown in a soil mixture $(1: 1: 1 \mathrm{sand} / \mathrm{loam} /$ compost $)$ in $7 \times 7 \times 8$-cm plastic pots. The seedlings were grown at $15^{\circ} \mathrm{C}$ in a growth chamber with a 16-h light period $\left(280 \mu \mathrm{E} \mathrm{m}^{-2} \mathrm{~s}^{-1}\right)$ for 10 days. The cotyledons were slightly wounded in the center of each lobe with a needle, and a $10-\mu \mathrm{l}$ drop of a pycnidiospore suspension $\left(10^{7}\right.$ pycnidiospores per $\mathrm{ml}$ ) was deposited on each wound. There were, therefore, four inoculation sites per plant. Inoculum was produced as described by De March et al. (9) and stored at $-20^{\circ} \mathrm{C}$ until used. Inoculum stored in this way remains viable for at least 2 years. A plastic cover was placed over inoculated plants to create an atmosphere

TABLE 1. List of A- and B-group isolates of Leptosphaeria maculans used in this study

\begin{tabular}{|c|c|c|c|c|c|}
\hline Isolate & Type & Location & Host & Group & Year of isolation \\
\hline A290 & $\mathrm{Sa}^{\mathrm{a}}$ & Le Rheu (France) & Brassica napus & A & 1985 \\
\hline A314 & $\mathrm{Pm}^{\mathrm{b}}$ & Le Rheu (France) & B. napus & A & 1985 \\
\hline A447 & $\mathrm{Pm}$ & Melford (Canada) & B. napus & A & 1987 \\
\hline A764 & $\mathrm{Sa}$ & Demanges (France) & B. napus & A & 1990 \\
\hline A775 and A813 & $\mathrm{Sa}$ & Le Rheu (France) & B. napus & A & 1990 \\
\hline A 824 & $\mathrm{Sa}$ & Demanges (France) & B. napus & A & 1990 \\
\hline A827 & $\mathrm{Sa}$ & Mondonville (France) & B. napus & A & 1990 \\
\hline A923 & $\mathrm{Sa}$ & Rigny (France) & B. napus & A & 1992 \\
\hline A924 & $\mathrm{Sa}$ & Mairy (France) & B. napus & A & 1992 \\
\hline A925 & $\mathrm{Sa}$ & Tressange (France) & B. napus & A & 1992 \\
\hline A929 and A930 & $\mathrm{Pm}$ & Edmonton (Canada) & B. napus & A & 1993 \\
\hline A931 and A932 & $\mathrm{Pm}$ & United Kingdom & B. napus & A & 1993 \\
\hline $\mathrm{Co} 1$ to $\mathrm{Co} 4$ & $\mathrm{Sa}$ & Le Rheu (France) & B. napus & A & 1993 \\
\hline Co7 to Co14 (except Co8 and Co10) & $\mathrm{Sa}$ & Le Rheu (France) & B. napus & A & 1993 \\
\hline$M X-1^{c}$ to $M X-3$ & $\mathrm{Sa}$ & Le Rheu (France) & MX line & A & 1993 \\
\hline MX1-2d to MX1-14 (except MX1-4) & $\mathrm{Sa}$ & Le Rheu (France) & MX line & A & 1993 \\
\hline MX2-1 to MX2-8 (except MX2-3) & $\mathrm{Sa}$ & Le Rheu (France) & MX line & A & 1993 \\
\hline MX3-1 to MX3-8 (except MX3-5) & $\mathrm{Sa}$ & Le Rheu (France) & MX line & A & 1993 \\
\hline MX4-1 to MX4-9 (except MX4-4 to MX4-6) & $\mathrm{Sa}$ & Le Rheu (France) & MX line & A & 1993 \\
\hline $\mathrm{MX}-\mathrm{S}^{\mathrm{e}}$ & $\mathrm{Pm}$ & Le Rheu (France) & MX line & A & 1994 \\
\hline $\mathrm{MXC1} 1^{\mathrm{e}}$ and $\mathrm{MXC} 2$ & $\mathrm{Pm}$ & Le Rheu (France) & MX line & A & 1994 \\
\hline $\mathrm{MX}-\mathrm{T} 1^{\mathrm{e}}$ and $\mathrm{MX}-\mathrm{T} 2$ & $\mathrm{Pm}$ & Le Rheu (France) & MX line & A & 1994 \\
\hline Es1 & $\mathrm{Pm}$ & Le Rheu (France) & Eruca sativa & A & 1994 \\
\hline Rs1 & $\mathrm{Pm}$ & Le Rheu (France) & Raphanus sativus & A & 1994 \\
\hline Sa1 & $\mathrm{Pm}$ & Le Rheu (France) & Sinapis arvensis & A & 1994 \\
\hline B867 & $\mathrm{Pm}$ & Dijon (France) & B. napus & B & 1985 \\
\hline B908 & $\mathrm{Pm}$ & Lyon (France) & B. napus & B & 1985 \\
\hline
\end{tabular}

${ }^{\mathrm{a}} \mathrm{Sa}=$ single-ascospore isolates.

${ }^{\mathrm{b}} \mathrm{Pm}=$ pycnidiospore-mass isolates.

${ }^{\mathrm{c}}$ Isolate number 1 originated from the MX line.

$\mathrm{d}$ The first digit designating the plant and the second digit designating the ascospore isolate recovered randomly from pseudothecia on the MX line (MX).

${ }^{\text {e }}$ Pycnidiospore-mass isolates obtained from leaf (L) stem (S and T) and canker (C) of the MX line. 
with $100 \%$ relative humidity $(\mathrm{RH})$. The plants were incubated in the dark at $20^{\circ} \mathrm{C}$ for $24 \mathrm{~h}$ in a growth chamber and then placed in an atmosphere with 80 to $90 \%$ RH (without plastic cover) with a 16-h photoperiod. The senescence of cotyledons was delayed by removing young leaves as soon as they appeared. We previously demonstrated that this does not affect the plant response $(\mathrm{H}$. Brun, unpublished data).

Assay conditions were standardized so that independent experiments could be compared. We used as a control an avirulent isolate (A314) previously used to select resistant plants among various progenies from $B$. napus-B. juncea interspecific crosses produced as part of the plant breeding scheme at the Plant Breeding Station. Resistance was correlated with three RAPD markers closely linked to the resistance gene (6). Two additional tests were also performed to assess the reliability of the results presented here (Table 2). The pathogenicity of one isolate that was avirulent (A314) and two that were virulent (MX4-7 and R2) on the MX line was evaluated on the MX line and 'Picra' (experiment 1) and on 'Westar' and the MX line (experiment 2), and the results were compared with those obtained with 'Westar', 'Picra', and the MX line (experiment 3 ).

Disease assessment. Fourteen days after inoculation, symptoms on cotyledons were scored using the 0 (no visible reaction) to 9 (total collapse of the tissue) rating scale of Williams and Delwiche (46). Each plant was considered to be a replicate, and each isolate was used to inoculate 16 plants of each genotype (giving 64 inoculation sites per genotype-isolate combination). A disease index (DI) was calculated according to the formula DI $=\Sigma\left(N_{i} \times i\right) / N_{t}$, in which $N_{i}$ is the number of inoculation sites with score $i$ (0 to 9$)$ and $N_{t}$ is the total number of inoculation sites (i.e., the number of well-developed cotyledon lobes). For each treatment, mean disease indices and standard deviations were calculated.

Pathogenicity is the ability of a pathogen to attack a species and it has two basic components (2). Virulence is a qualitative trait of the isolates and defines the compatibility of the host-pathogen interaction. In this case, incompatibility (i.e., avirulence in the isolate and resistance in the host) was expressed as a HR-like response. Aggressiveness characterizes the ability of virulent isolates to induce more or less severe symptoms. The following pathogenicity classes were defined: DI $<4$ indicated an incompatible interaction (avirulent isolates), $4 \leq \mathrm{DI}<6$ indicated moderate aggressiveness, and DI $\geq 6$ indicated that the isolate was highly aggressive.

Data analysis. The distributions obtained were not normal and the variances were not homogeneous, so nonparametric tests were used. The three independent experiments were tested using the Wilcoxon test $(\alpha=0.05)$ under PROC NPAR1WAY in the Statistical Analysis System (SAS, Institute, Inc., Cary, NC) to compare the distributions of the plant disease indices for each isolate-cultivar combination. The results obtained with the MX line and 'Picra' were compared between experiments 1 and 3 . The results obtained with 'Westar' and the MX line were compared between experiments 2 and 3. The Kruskal and Wallis test $(\alpha=0.05)$ was used to compare the various isolates from oilseed rape and the MX line within A and B groups. Isolates were classified into homogeneous groups by the Noether test (38) using the mean rank from the Kruskal and Wallis test. The distributions of isolates between the two populations recovered from oilseed rape cultivars and from the MX line were compared using the $\chi^{2}$ test $(\alpha=0.05)$, the mean disease indices being grouped into eight classes, 1 to 2,2 to 3 , and so on, to 8 to 9 .

\section{RESULTS}

Reproducibility of the test. Isolates (A314, MX4-7, and R2) were assigned to the same pathogenicity classes according to genotype in all experiments (Table 2). For instance, isolate A314 was avirulent on both the MX line and 'Picra', but was virulent and highly aggressive on 'Westar' in the cotyledon tests in this study. The Wilcoxon test was used to compare the distribution of indices. There was no difference between experiments for any isolate-cultivar combination, except for 'Picra' inoculated with isolate R2. However, isolate R2 was avirulent on 'Picra' in both experiments.

Pathogenicity of A-group isolates recovered from Brassica genotypes. The Kruskal and Wallis test indicated that there were significant differences between isolates for each genotype. The Noether test classified the isolates into several (six to eight) homogeneous groups that overlapped for each genotype. We attempted to assign the isolates to the three pathogenicity classes.

The 37 A-group isolates from B. napus cultivars were avirulent to virulent on the MX line, whereas they were all virulent on 'Westar'. All these isolates caused a HR-type response on $B$. juncea 'Picra' (Table 3).

The 65 A-group isolates from the MX line were also avirulent to virulent on the MX line, and all but one isolate, R15 (DI of $2.9 \pm$ 1.8), were virulent on 'Westar'. However, R15 belonged to the same homogeneous group as the moderately aggressive isolates. All but two isolates (MX-C1 and MX1-13) were avirulent on 'Picra', but MX-C1 and MX1-13 belonged to the same homogeneous group as other avirulent isolates (Table 4). Isolates recovered from a single plant of the MX line differed in pathogenicity on the MX line (e.g., MX2-1 [DI of $1.9 \pm 0.9$ ] was avirulent, whereas MX2-4 [DI of $8.8 \pm 0.7]$ was virulent and highly aggressive). They were classified into two different homogeneous groups.

The pathogenicity of isolates recovered from B. napus was compared with that of isolates from the MX line. There was no difference between the two populations on 'Westar' and 'Picra', whereas there were large differences $\left(\chi^{2}=11.23, P=0.0038\right)$ on the MX line (Fig. 1). The proportion of isolates in each DI class differed between the two populations, the proportion of isolates virulent on the MX line being higher among the isolates recovered from this line.

Pathogenicity of isolates in relation to geographic origin. The pathogenicity of French isolates of $L$. maculans collected from various cultivars of $B$. napus grown in several locations differed (Table 3). Only isolates A923 (DI of $6.8 \pm 2.0$ ) from Rigny and A759 (DI of $5.5 \pm 1.5$ ) from Delmes were virulent on the MX line. The isolates from Le Rheu (France) differed in pathogenicity on the MX line and included both virulent isolates (Co12, Co4, Co18, Co13, Co22, Co17, Co11, and Co24) and one avirulent isolate

TABLE 2. Three experiments in which Leptosphaeria maculans isolates avirulent (A314) and virulent (MX4-7 and R2) on the MX line were evaluated for pathogenicity on cotyledons of 'Picra', 'Westar', and the MX line to assess the reliability of the results ${ }^{\mathrm{a}}$

\begin{tabular}{|c|c|c|c|c|c|c|c|}
\hline \multirow[b]{2}{*}{ Isolates } & \multicolumn{2}{|c|}{ Experiment $1^{\mathrm{b}}$} & \multicolumn{2}{|c|}{ Experiment $2^{c}$} & \multicolumn{3}{|c|}{ Experiment $3^{\mathrm{d}}$} \\
\hline & MX & 'Picra' & 'Westar' & MX & 'Westar' & MX & 'Picra' \\
\hline A314 & $1.9 \pm 0.8$ & $1.3 \pm 0.4$ & $7.7 \pm 0.9$ & $1.1 \pm 0.2$ & $6.6 \pm 1.4$ & $1.6 \pm 0.5$ & $1.1 \pm 0.2$ \\
\hline MX4-7 & $9.0 \pm 0.0$ & $1.8 \pm 0.6$ & $9.0 \pm 0.0$ & $8.9 \pm 0.1$ & $8.5 \pm 0.6$ & $8.6 \pm 0.6$ & $1.9 \pm 0.5$ \\
\hline
\end{tabular}

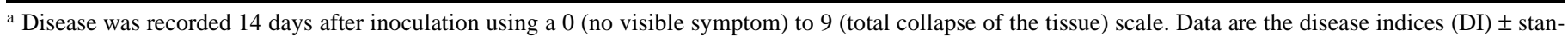
dard deviation. Interaction phenotype: DI $<4=$ resistant; $4 \leq \mathrm{DI}<6=$ moderately resistant; and DI $\geq 6=$ susceptible.

b 18 plants inoculated per genotype.

c 10 plants inoculated per genotype.

d 16 plants inoculated per genotype. 
(A314). All Canadian and English isolates were avirulent on the MX line.

Pathogenicity of B-group isolates recovered from Brassica genotypes. All B-group isolates tested were highly aggressive on the MX line and 'Westar', irrespective of their origin (Table 5). Most of the B-group isolates tested were virulent on cotyledons of 'Picra', but isolate B867 was avirulent and significantly different from the other isolates.

Pathogenicity of A- and B-group L. maculans isolates recovered from other crucifers. A-group isolates were collected from other crucifer species. Isolate $\mathrm{Sa} 1$, recovered from $S$. arvensis, was highly aggressive on 'Westar' and the MX line. Isolate Rs1, from $R$. sativus was avirulent on all three genotypes (Table 3). Isolate Es1, recovered from $E$. sativa, was avirulent on the MX line and 'Picra', but was moderately aggressive on 'Westar'. We also assessed the pathogenicity of four B-group isolates, recovered from wild and other cultivated cruciferous hosts, on these three genotypes (Table 5). Isolate Es2 (from E. sativa) was avirulent on 'Picra', but the other isolates obtained from Raphanobrassica (RBMN), S. arvensis (Sa2), and R. sativus (Rs2) were all virulent on all the genotypes tested.

TABLE 3. Pathogenicity of A-group isolates of Leptosphaeria maculans recovered from Brassica napus and other crucifers on cotyledons of the three genotypes

\begin{tabular}{|c|c|c|c|}
\hline \multirow[b]{2}{*}{ Isolate } & \multicolumn{3}{|c|}{ Disease index ${ }^{a}$} \\
\hline & MX & 'Westar' & 'Picra' \\
\hline Co12 & $7.0 \pm 2.8$ & $8.0 \pm 2.0$ & $1.7 \pm 0.7$ \\
\hline A923 & $6.8 \pm 2.0$ & $9.0 \pm 0.0$ & $2.0 \pm 1.4$ \\
\hline $\mathrm{Co} 4$ & $6.6 \pm 2.1$ & $7.0 \pm 2.1$ & $1.9 \pm 0.8$ \\
\hline Co18 & $6.3 \pm 1.8$ & $8.8 \pm 0.7$ & $2.2 \pm 1.1$ \\
\hline Co13 & $6.1 \pm 2.8$ & $9.0 \pm 0.0$ & $1.5 \pm 0.6$ \\
\hline $\mathrm{Co} 22$ & $6.0 \pm 1.6$ & $7.9 \pm 1.3$ & $2.4 \pm 1.2$ \\
\hline Co17 & $5.8 \pm 3.0$ & $9.0 \pm 0.0$ & $1.6 \pm 1.2$ \\
\hline Co11 & $5.6 \pm 2.3$ & $7.9 \pm 1.9$ & $1.5 \pm 0.7$ \\
\hline A759 & $5.5 \pm 1.5$ & $9.0 \pm 0.0$ & $2.5 \pm 1.1$ \\
\hline Co24 & $4.4 \pm 2.0$ & $6.3 \pm 1.7$ & $1.5 \pm 1.0$ \\
\hline A447 & $3.4 \pm 1.2$ & $9.0 \pm 0.0$ & $1.7 \pm 0.7$ \\
\hline Co1 & $3.4 \pm 1.7$ & $7.0 \pm 2.8$ & $1.3 \pm 0.7$ \\
\hline $\mathrm{Co} 2$ & $3.3 \pm 1.2$ & $7.0 \pm 2.2$ & $2.2 \pm 1.1$ \\
\hline Co14 & $3.2 \pm 1.4$ & $5.7 \pm 2.5$ & $0.6 \pm 0.7$ \\
\hline A925 & $3.1 \pm 1.1$ & $8.8 \pm 1.0$ & $0.9 \pm 0.8$ \\
\hline A764 & $3.0 \pm 1.3$ & $9.0 \pm 0.0$ & $1.2 \pm 0.5$ \\
\hline Co3 & $3.0 \pm 1.4$ & $6.8 \pm 2.5$ & $1.7 \pm 0.9$ \\
\hline A932 & $2.9 \pm 1.3$ & $8.4 \pm 2.0$ & $1.5 \pm 0.9$ \\
\hline A824 & $2.8 \pm 1.0$ & $8.8 \pm 1.2$ & $1.0 \pm 0.3$ \\
\hline Co21 & $2.8 \pm 1.4$ & $8.8 \pm 0.9$ & $0.8 \pm 1.0$ \\
\hline Co25 & $2.7 \pm 1.2$ & $8.4 \pm 1.3$ & $1.6 \pm 0.8$ \\
\hline A290 & $2.6 \pm 1.0$ & $9.0 \pm 0.0$ & $0.9 \pm 0.4$ \\
\hline A813 & $2.6 \pm 1.1$ & $8.9 \pm 0.5$ & $1.1 \pm 0.4$ \\
\hline $\mathrm{Co} 23$ & $2.4 \pm 0.7$ & $9.0 \pm 0.0$ & $3.1 \pm 1.6$ \\
\hline A775 & $2.4 \pm 1.1$ & $9.0 \pm 0.0$ & $0.9 \pm 0.4$ \\
\hline A924 & $2.2 \pm 0.9$ & $8.1 \pm 1.6$ & $1.0 \pm 0.5$ \\
\hline Co27 & $2.2 \pm 1.2$ & $4.7 \pm 2.3$ & $1.8 \pm 0.8$ \\
\hline Co29 & $2.2 \pm 1.1$ & $5.3 \pm 2.4$ & $0.8 \pm 0.8$ \\
\hline Co9 & $2.1 \pm 0.6$ & $9.0 \pm 0.0$ & $1.7 \pm 1.2$ \\
\hline A931 & $2.0 \pm 0.9$ & $8.8 \pm 0.8$ & $1.1 \pm 0.5$ \\
\hline A929 & $2.0 \pm 0.9$ & $7.1 \pm 2.1$ & $0.9 \pm 0.2$ \\
\hline Co7 & $1.9 \pm 0.4$ & $9.0 \pm 0.0$ & $2.8 \pm 1.5$ \\
\hline A827 & $1.8 \pm 1.0$ & $7.6 \pm 1.6$ & $0.9 \pm 0.3$ \\
\hline A922 & $1.8 \pm 1.1$ & $6.8 \pm 2.1$ & $0.7 \pm 0.4$ \\
\hline A314 & $1.5 \pm 0.9$ & $6.6 \pm 2.3$ & $0.8 \pm 0.6$ \\
\hline A930 & $0.2 \pm 0.4$ & $5.6 \pm 2.3$ & $0.0 \pm 0.0$ \\
\hline A901 & $\mathrm{NT}^{\mathrm{b}}$ & $8.9 \pm 0.5$ & $1.0 \pm 0.5$ \\
\hline Sa1 & $8.1 \pm 0.9$ & $9.0 \pm 0.0$ & $4.4 \pm 0.8$ \\
\hline Es1 & $3.5 \pm 1.0$ & $5.3 \pm 0.6$ & $3.4 \pm 0.7$ \\
\hline Rs1 & $2.0 \pm 0.8$ & $2.2 \pm 0.6$ & $1.8 \pm 0.5$ \\
\hline
\end{tabular}

${ }^{a}$ Disease was recorded 14 days after inoculation using a 0 (no visible symptom) to 9 (total collapse of the tissue) scale. Data are the disease indices (DI) of 16 replicates of each genotype-isolate combination \pm standard deviation. Interaction phenotype: DI $<4=$ resistant; $4 \leq \mathrm{DI}<6=$ moderately resistant; and DI $\geq 6$ = susceptible.

${ }^{\mathrm{b}} \mathrm{NT}=$ not tested.
TABLE 4. Pathogenicity of A-group isolates of Leptosphaeria maculans recovered from the MX line on cotyledons of the three genotypes

\begin{tabular}{|c|c|c|c|}
\hline \multirow[b]{2}{*}{ Isolate } & \multicolumn{3}{|c|}{ Disease index $^{\mathrm{a}}$} \\
\hline & MX & 'Westar' & 'Picra' \\
\hline MX-T2 & $8.9 \pm 0.5$ & $8.5 \pm 1.3$ & $2.7 \pm 1.3$ \\
\hline MX2-4 & $8.8 \pm 0.7^{b}$ & $8.9 \pm 0.4$ & $2.7 \pm 1.1$ \\
\hline MX-S & $8.8 \pm 0.7$ & $9.0 \pm 0.0$ & $3.0 \pm 1.7$ \\
\hline MX-C1 & $8.6 \pm 1.2$ & $8.7 \pm 1.1$ & $4.1 \pm 1.5$ \\
\hline MX4-2 & $8.6 \pm 1.1$ & $8.9 \pm 1.0$ & $2.2 \pm 1.4$ \\
\hline MX4-3 & $8.6 \pm 1.0$ & $7.6 \pm 1.9$ & $0.7 \pm 0.7$ \\
\hline MX4-7 & $8.6 \pm 0.9$ & $8.5 \pm 0.9$ & $1.7 \pm 1.0$ \\
\hline R2 & $8.5 \pm 1.5$ & $8.4 \pm 1.3$ & $1.6 \pm 0.9$ \\
\hline R6 & $8.5 \pm 1.5$ & $8.6 \pm 1.1$ & $2.3 \pm 1.0$ \\
\hline MX-C2 & $8.5 \pm 1.1$ & $8.5 \pm 1.2$ & $3.4 \pm 1.4$ \\
\hline MX4-9 & $8.1 \pm 2.0$ & $8.5 \pm 1.2$ & $3.2 \pm 1.9$ \\
\hline R4 & $8.1 \pm 1.7$ & $8.6 \pm 1.3$ & $1.9 \pm 1.0$ \\
\hline R7 & $8.1 \pm 1.6$ & $8.9 \pm 0.6$ & $1.9 \pm 0.5$ \\
\hline R8 & $8.1 \pm 1.5$ & $9.0 \pm 0.0$ & $2.5 \pm 1.4$ \\
\hline R13 & $7.9 \pm 1.8$ & $9.0 \pm 0.0$ & $1.4 \pm 0.6$ \\
\hline MX-1 & $7.6 \pm 1.6$ & $8.6 \pm 1.5$ & $2.0 \pm 1.3$ \\
\hline R9 & $7.3 \pm 2.2$ & $8.7 \pm 1.3$ & $2.8 \pm 1.3$ \\
\hline R14 & $7.2 \pm 2.5$ & $7.5 \pm 2.3$ & $1.3 \pm 0.9$ \\
\hline MX-T1 & $7.0 \pm 2.1$ & $7.9 \pm 1.7$ & $1.4 \pm 0.4$ \\
\hline MX2-2 & $6.8 \pm 2.5$ & $7.7 \pm 1.7$ & $2.3 \pm 1.4$ \\
\hline R18 & $6.5 \pm 1.8$ & $8.7 \pm 1.1$ & $1.0 \pm 0.6$ \\
\hline MX-3 & $6.3 \pm 2.1$ & $7.5 \pm 1.9$ & $2.5 \pm 1.3$ \\
\hline MX4-8 & $6.0 \pm 2.6$ & $6.3 \pm 1.4$ & $2.7 \pm 1.5$ \\
\hline MX2-8 & $5.9 \pm 2.4$ & $8.9 \pm 0.5$ & $2.3 \pm 1.1$ \\
\hline MX2-5 & $5.9 \pm 2.1$ & $8.5 \pm 1.4$ & $3.1 \pm 1.8$ \\
\hline MX1-13 & $5.8 \pm 1.8$ & $8.9 \pm 0.4$ & $4.3 \pm 1.8$ \\
\hline R23 & $5.8 \pm 1.6$ & $9.0 \pm 0.0$ & $3.4 \pm 1.8$ \\
\hline MX1-11 & $5.3 \pm 2.1$ & $8.6 \pm 1.1$ & $1.9 \pm 1.2$ \\
\hline $\mathrm{R} 1$ & $5.2 \pm 2.3$ & $6.5 \pm 1.9$ & $1.5 \pm 0.8$ \\
\hline MX1-8 & $5.2 \pm 1.8$ & $8.9 \pm 1.1$ & $3.9 \pm 1.8$ \\
\hline R21 & $4.9 \pm 2.0$ & $7.8 \pm 1.7$ & $1.3 \pm 0.7$ \\
\hline MX3-8 & $4.7 \pm 1.7$ & $9.0 \pm 0.0$ & $1.9 \pm 1.1$ \\
\hline MX1-9 & $4.5 \pm 1.9$ & $8.6 \pm 1.0$ & $1.7 \pm 1.0$ \\
\hline R10 & $4.4 \pm 2.2$ & $9.0 \pm 0.0$ & $2.6 \pm 1.3$ \\
\hline MX1-14 & $4.4 \pm 2.2$ & $7.1 \pm 2.0$ & $1.8 \pm 1.1$ \\
\hline MX3-2 & $4.4 \pm 1.8$ & $8.3 \pm 1.1$ & $1.7 \pm 1.2$ \\
\hline MX-2 & $4.2 \pm 3.7$ & $7.9 \pm 2.9$ & $1.3 \pm 0.8$ \\
\hline $\mathrm{R} 20$ & $4.1 \pm 1.4$ & $5.4 \pm 1.7$ & $1.3 \pm 0.5$ \\
\hline MX1-12 & $3.9 \pm 1.5$ & $7.0 \pm 2.1$ & $1.1 \pm 0.7$ \\
\hline MX4-1 & $3.8 \pm 1.3$ & $8.7 \pm 1.6$ & $1.4 \pm 0.9$ \\
\hline MX3-7 & $3.7 \pm 1.8$ & $8.8 \pm 1.1$ & $2.7 \pm 1.5$ \\
\hline R5 & $3.6 \pm 1.8$ & $9.0 \pm 0.0$ & $1.5 \pm 0.7$ \\
\hline MX2-7 & $3.6 \pm 1.5$ & $6.2 \pm 1.3$ & $1.5 \pm 0.6$ \\
\hline MX1-10 & $3.3 \pm 1.6$ & $8.7 \pm 1.3$ & $1.5 \pm 1.0$ \\
\hline MX2-6 & $3.2 \pm 1.5$ & $6.4 \pm 1.7$ & $1.4 \pm 0.8$ \\
\hline R16 & $3.1 \pm 2.2$ & $9.0 \pm 0.3$ & $1.6 \pm 0.9$ \\
\hline R24 & $3.0 \pm 1.4$ & $8.9 \pm 1.1$ & $1.6 \pm 0.9$ \\
\hline MX3-1 & $2.9 \pm 1.7$ & $8.2 \pm 1.9$ & $2.0 \pm 1.1$ \\
\hline MX1-5 & $2.7 \pm 2.6$ & $5.3 \pm 1.5$ & $1.3 \pm 1.1$ \\
\hline R22 & $2.6 \pm 1.2$ & $9.0 \pm 0.0$ & $2.2 \pm 1.0$ \\
\hline MX3-4 & $2.6 \pm 0.9$ & $8.5 \pm 1.2$ & $2.4 \pm 1.7$ \\
\hline R11 & $2.5 \pm 2.0$ & $9.0 \pm 0.0$ & $1.6 \pm 0.9$ \\
\hline R12 & $2.5 \pm 1.5$ & $8.8 \pm 0.8$ & $1.7 \pm 0.9$ \\
\hline R25 & $2.5 \pm 1.2$ & $8.9 \pm 0.5$ & $1.1 \pm 0.4$ \\
\hline MX1-2 & $2.4 \pm 1.6$ & $6.2 \pm 1.3$ & $2.3 \pm 1.0$ \\
\hline MX3-3 & $2.3 \pm 0.8$ & $7.3 \pm 2.3$ & $2.0 \pm 0.9$ \\
\hline MX1-3 & $2.2 \pm 2.0$ & $5.8 \pm 1.9$ & $2.5 \pm 1.4$ \\
\hline R19 & $2.2 \pm 0.8$ & $9.0 \pm 0.0$ & $0.7 \pm 0.6$ \\
\hline R3 & $2.1 \pm 1.0$ & $8.6 \pm 1.1$ & $1.4 \pm 0.8$ \\
\hline MX3-6 & $2.0 \pm 1.2$ & $7.0 \pm 2.6$ & $0.8 \pm 0.8$ \\
\hline R15 & $1.9 \pm 1.7$ & $2.1 \pm 1.8$ & $0.9 \pm 0.3$ \\
\hline MX2-1 & $1.9 \pm 0.9$ & $5.0 \pm 1.3$ & $0.9 \pm 0.5$ \\
\hline MX1-6 & $1.8 \pm 1.5$ & $5.7 \pm 1.8$ & $0.9 \pm 0.8$ \\
\hline MX1-7 & $1.6 \pm 1.6$ & $5.2 \pm 1.6$ & $1.6 \pm 1.1$ \\
\hline R17 & $1.2 \pm 1.0$ & $5.7 \pm 1.3$ & $0.3 \pm 0.4$ \\
\hline
\end{tabular}

${ }^{a}$ Disease was recorded 14 days after inoculation using a 0 (no visible symptom) to 9 (total collapse of the tissue) scale. Data are the disease indices (DI) of 16 replicates of each genotype-isolate combination \pm standard deviation. Interaction phenotype: DI $<4=$ resistant; $4 \leq \mathrm{DI}<6=$ moderately resistant; and DI $\geq 6$ = susceptible.

${ }^{\mathrm{b}}$ Bold values are the values mentioned in the text. 


\section{DISCUSSION}

Between 1977 and 1983, blackleg was successfully controlled in France and other European countries by exploiting the adult plant resistance of the French $B$. napus cultivar Jet Neuf (31; M. Renard and $\mathrm{H}$. Brun, unpublished data). However, most cultivars currently in use do not have strong enough resistance to blackleg throughout plant development (juvenile and adult stages). The B. napus-B. juncea recombinant line (MX), selected using the A-group isolate A314, has strong cotyledon resistance to some A-group isolates from oilseed rape cultivars. This line is highly resistant in field conditions to $L$. maculans populations associated with B. napus cultivars (6). Assessment of the resistance of the MX line at the cotyledon stage to populations of $L$. maculans from various origins and of the effect of this resistance on the evolution of the pathogen populations may facilitate more effective use of this new source of resistance.

Variation in pathogenicity among B-group isolates. All Bgroup isolates tested were virulent on the MX line. Thus, the re-
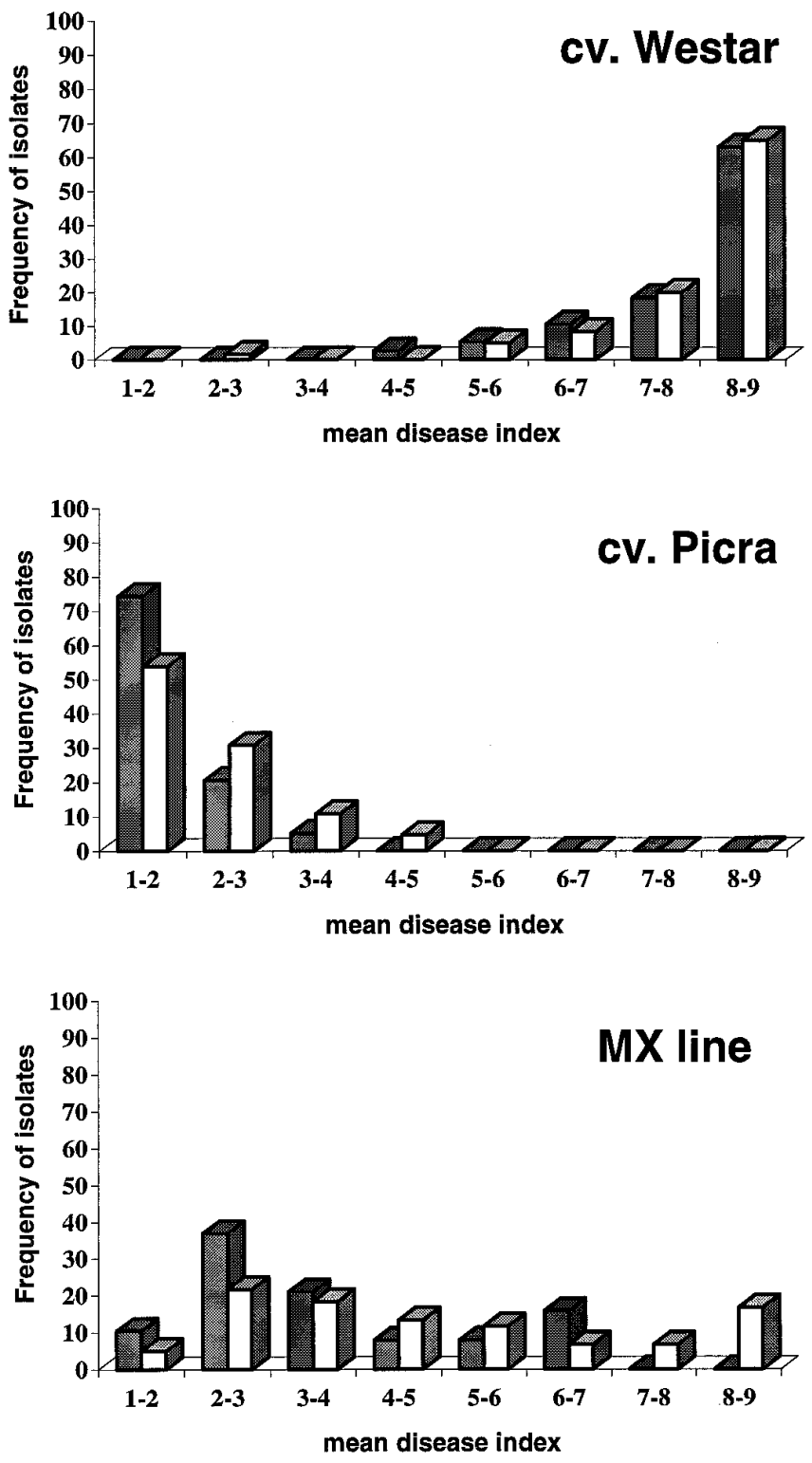

Fig. 1. Frequencies in each mean disease index of A-group isolates in populations of Leptosphaeria maculans recovered from Brassica napus cultivars (black bars) and from the Brassica napus-B. juncea recombinant line MX (white bars) according to their pathogenicity on B. napus 'Westar', B. juncea 'Picra', and the MX line. sistance conferred by the Jlml gene in B. napus was ineffective against B-group isolates. Resistance to B-group isolates was not used as a selection criterion in the production of the MX line, so this lack of resistance is not surprising. The resistance of 'Picra' to some B-group isolates suggests that $B$. juncea may possess genes conferring resistance to B-group isolates. These putative genes could be exploited to increase the resistance of B. napus to this group of L. maculans populations. However, we need to know whether this resistance is effective throughout the life of the plant.

Our results for 'Westar' and 'Picra' are consistent with previous data concerning the pathogenicity of B. juncea-related B-group isolates (42) and the pathogenicity of this group of isolates on cotyledons of many crucifer species $(11,17)$. We found that other wild cruciferous host species may also act as reservoirs for Bgroup isolates that cause disease on Brassica species.

Variation in the pathogenicity of A-group isolates. The susceptible standard 'Westar' can be used to detect isolates lacking virulence genes effective against $B$. napus. The moderate to high susceptibility of 'Westar' to all but one of the A-group isolates tested was consistent with previous observations $(18,21,42)$. Among the A-group isolates, the avirulent isolate R15 (recovered from the MX line) lacked virulence on 'Westar', even though it was classified in the same homogeneous group as moderately aggressive isolates, probably because of the large number of two-way comparisons performed. $B$. juncea 'Picra' had a HR-type resistance to most of the 105 A-group isolates tested. This strong cotyledon resistance to blackleg is conferred by two or three major genes in $B$. juncea $(24,30,44)$. Our results show that there is extensive genetic diversity within local A-group populations and even between isolates recovered from pseudothecia on the same stubble. Indeed, virulent and avirulent A-group isolates were recovered from the same MX line plant, suggesting that there was variation at the single plant level. The recovery of isolates avirulent on the MX line from pseudothecia produced on this resistant line is surprising. It is possible that some isolates are avirulent at the cotyledon stage but virulent at the adult stage, as suggested by Somda et al. (43) for 'Picra'. Alternatively, there may be genes suppressing the expression of avirulence genes in L. maculans isolates. Indeed, Ellingboe (10) demonstrated that some crosses between two isolates of Magnaporthe grisea, both of which were virulent on a particular rice cultivar, were found to give some progenies that were avirulent on the same cultivar. They concluded that there was a

TABLE 5. Pathogenicity of B-group isolates of Leptosphaeria maculans recovered from the MX line, Brassica napus cultivars, and other crucifers on cotyledons of the three genotypes

\begin{tabular}{lccc}
\hline & \multicolumn{3}{c}{ Disease index $^{\mathrm{a}}$} \\
\cline { 2 - 4 } Isolate & MX & 'Westar' & 'Picra' \\
\hline MX-4 & $9.0 \pm 0.0$ & $9.0 \pm 0.0$ & $8.5 \pm 1.6$ \\
MX-5 & $9.0 \pm 0.0$ & $9.0 \pm 0.0$ & $6.7 \pm 2.4$ \\
MX-6 & $9.0 \pm 0.0$ & $9.0 \pm 0.0$ & $7.2 \pm 3.2$ \\
MX-L & $8.8 \pm 1.1$ & $8.1 \pm 1.5$ & $4.6 \pm 2.7$ \\
MX-7 & $8.7 \pm 1.5$ & $9.0 \pm 0.0$ & $7.4 \pm 2.5$ \\
MX-8 & $8.4 \pm 1.7$ & $7.8 \pm 2.6$ & $7.3 \pm 2.8$ \\
B980 & $9.0 \pm 0.0$ & $7.6 \pm 2.2$ & $6.8 \pm 3.0$ \\
B981 & $9.0 \pm 0.0$ & $9.0 \pm 0.0$ & $7.8 \pm 2.3$ \\
B867 & $9.0 \pm 0.0$ & $8.7 \pm 0.8$ & $2.6 \pm 1.4$ \\
B908 & $8.9 \pm 0.5$ & NT ${ }^{\mathrm{b}}$ & $4.8 \pm 2.1$ \\
RBMN & $9.0 \pm 0.0$ & $9.0 \pm 0.0$ & $7.2 \pm 2.3$ \\
Rs2 & $9.0 \pm 0.0$ & $8.5 \pm 0.9$ & $6.8 \pm 1.6$ \\
Sa2 & $8.8 \pm 0.4$ & $8.7 \pm 0.9$ & $5.1 \pm 2.4$ \\
Es2 & $7.9 \pm 1.2$ & $8.2 \pm 0.9$ & $3.7 \pm 1.7$ \\
\hline
\end{tabular}

a Disease was recorded 14 days after inoculation using a 0 (no visible symptom) to 9 (total collapse of the tissue) scale. Data are the disease indices (DI) of 16 replicates of each genotype-isolate combination \pm standard deviation. Interaction phenotype: DI $<4=$ resistant; $4 \leq \mathrm{DI}<6=$ moderately resistant; and DI $\geq 6=$ susceptible.

${ }^{\mathrm{b}} \mathrm{NT}=$ not tested. 
dominant suppressor of an avirulence gene in one of the virulent parents. Thus, it is of vital importance to study the genetic basis of the avirulence/virulence of $L$. maculans on the MX line.

There were differences in virulence among A-group isolates recovered from $B$. napus and used to inoculate cotyledons of the MX line. B. napus isolates from Canada and England were avirulent on the MX line. Virulent isolates were detected in two French locations. Isolates able to attack the MX line were more abundant among those recovered from the MX line at Le Rheu (France) than among those recovered from oilseed rape cultivars. This result suggests that the line exerts a selection pressure on $L$. maculans populations and, therefore, that $L$. maculans populations may adapt and increase on the MX line in the areas where B. napus cultivars are grown. Only one of the two or three putative resistance genes has been transferred into B. napus. This may account for the resistance spectrum of the MX line being narrower than that of the $B$. juncea cultivar.

We have shown that there are L. maculans populations capable of overcoming the resistance conferred by the Jlml gene. The occurrence of such pathotypes suggests that the $J \mathrm{~lm} 1$ gene is race specific and raises concerns about the use of the Jlml resistance gene in France. Such virulent pathotypes are currently present at a low level on B. napus cultivars, but may become abundant if cultivars with $\mathrm{Jlm} 1$ resistance are introduced.

Only one isolate recovered from $S$. arvensis was tested, but our results suggest that this species could be infected by isolates virulent on oilseed rape whether or not the $J \mathrm{~lm} 1$ gene is present. $S$. arvensis is widespread in the B. napus growing areas of France and is, therefore, a significant source of inoculum for blackleg in oilseed rape crops. In contrast to the results obtained with Canadian isolates $(22,27)$, French $L$. maculans isolates recovered from wild crucifers were similar to A- or B-group isolates. However, the role played by infected wild crucifers in the epidemiology of blackleg in France is unknown. Further studies involving collections of L. maculans isolated from various wild crucifers to determine their role in the evolution and maintenance of virulent pathotypes, especially against new resistance genes, would be useful. This information is necessary for the successful management of blackleg resistance in oilseed rape cultivars.

Consequences for breeding strategies. We have demonstrated that the monogenic resistance originating from the $B$. juncea $\mathrm{B}$ genome can be overcome in the MX line at the cotyledon stage by virulent isolates of $L$. maculans found in the B. napus growing areas of France. The frequency of virulent isolates increases if the MX line is grown in the field. Thus, alternative strategies for breeding B. napus with blackleg resistance are required. Resistance gene pyramiding had been successfully used in the wheat-rust pathosystem (26). However, Kousik and Ritchie (19) reported that the improvement in resistance to the pepper bacterial spot pathogen (Xanthomonas campestris pv. vesicatoria), obtained with two genes used simultaneously, is not effective against some isolates. Gene pyramiding was developed to improve cultivar resistance and is well documented in many pathosystems $(1,26)$, but it has yet to be achieved in the B. napus-L. maculans pathosystem. Therefore, the effect on blackleg control of resistance gene pyramiding in a particular oilseed rape genotype is unpredictable. The diversification of resistance sources may be of value for developing resistant oilseed rape genotypes. Isolates virulent and highly aggressive on the MX line but avirulent on 'Picra' may make it possible to identify the remaining $B$. juncea resistance genes in progeny resulting from the interspecific hybridization of $B$. napus and $B$. juncea. They could also be used to screen Brassica genus and other crucifer species for genes conferring complementary resistance. Lines with $\mathrm{Jlm} 1$ resistance or with resistance originating from $B$. nigra are available (7), so it would be of great value to combine these resistance sources. The pyramiding of $\mathrm{Jlml}$ and other resistance genes into French B. napus cultivars with partial adult plant resistance (e.g., 'Darmor') could improve resistance to L. maculans at all plant growth stages. All these strategies require such genotypes to be tested under various field conditions and over several years before development on a commercial scale, because stem canker, a manifestation of blackleg disease, is economically important. Efficient control of this endemic disease should combine the use of resistant cultivars with agricultural practices to reduce inoculum pressure (e.g., destruction of infected residues after harvesting) and the eradication of wild cruciferous hosts within and around fields containing oilseed rape crops.

\section{ACKNOWLEDGMENTS}

This work was partially supported by a grant from CETIOM, PROMOSOL, and AIP-INRA-GEVES "Coévolution des populations végétales domestiquées, face à leurs agents pathogènes ou ravageurs." We thank A. M. Chèvre, D. Andrivon, and M. Trottet for reviewing the manuscript.

\section{LITERATURE CITED}

1. Ahmed, H. U., Finckh, M. R., Alfonso, R. F., and Mundt, C. C. 1997. Epidemiology effect of gene deployment strategies on bacterial blight of rice. Phytopathology 87:66-70.

2. Andrivon, D. 1993. Nomenclature for pathogenicity and virulence: The need for precision. Phytopathology 83:889-890.

3. Balesdent, M. H., Gall, C., Robin, P., and Rouxel, T. 1992. Intraspecific variation in soluble mycelial protein and esterase patterns of Leptosphaeria maculans French isolates. Mycol. Res. 96:677-684.

4. Bonman, J. M., Gabrielson, R. L., Williams, P. H., and Delwiche, P. A. 1981. Virulence of Phoma lingam to cabbage. Plant Dis. 65:865-867.

5. Brun, H., Levivier, S., Eber, F., Renard, M., and Chèvre, A. M. 1997. Electrophoretic analysis of natural populations of Leptosphaeria maculans directly from leaf lesions. Plant Pathol. 46:147-154.

6. Chèvre, A. M., Barret, P., Eber, F., Dupuy, P., Brun, H., Tanguy, X., and Renard, M. 1997. Selection of stable Brassica napus-Brassica juncea recombinant lines resistant to blackleg (Leptosphaeria maculans) 1: Identification of molecular markers, chromosomal and genomic origin of the introgression. Theor. Appl. Genet. 95:1104-1111.

7. Chèvre, A. M., Eber, F., This, P., Tanguy, X., Brun, H., Delseny, M., and Renard, M. 1996. Characterization of Brassica nigra chromosomes and of blackleg resistance in B. napus-B. nigra addition lines. Plant Breed. 115:113-118.

8. Cunningham, G. H. 1927. Dry-rot of swedes and turnips: Its causes and control. N.Z. Dep. Agric. Bull. 133:51.

9. De March, G., Séguin-Swartz, G., and Petrie, G. A. 1986. Virulence and culture filtrate phytotoxicity in Leptosphaeria maculans: Perspectives for in vitro selection. Can. J. Plant Pathol. 8:422-428.

10. Ellingboe, A. H. 1992. Segregation of avirulence/virulence on three rice cultivars in 16 crosses of Magnaporthe grisea. Phytopathology 82:597-601.

11. Gall, C., Balesdent, M. H., Desthieux, I., Robin, P., and Rouxel, T. 1995. Polymorphism of Tox0 Leptosphaeria maculans isolates as revealed by soluble protein and isozyme electrophoresis. Mycol. Res. 99:221-229.

12. Gladders, P. 1995. Canker on winter oilseed rape: Occurrence in eastern England 1977-1995 and prospects for forecasting and control. Blackleg News 5:7-8.

13. Goodwin, P. H., and Annis, S. L. 1991. Rapid identification of genetic variation and pathotype of Leptosphaeria maculans by random amplified polymorphic DNA assay. Appl. Environ. Microbiol. 57:2482-2486.

14. Hall, R., Peters, R. D., and Assabagui, R. A. 1993. Occurrence and impact of blackleg on oilseed rape in Ontario. Can. J. Plant Pathol. 15:305-313.

15. Hill, C. B. 1991. Inheritance of seedling blackleg resistance in canola. Pages 296-291 in: Proc. Int. Rapeseed Congress, 8th. D. I. McGregor, ed., Saskatoon, Saskatchewan, Canada.

16. Johnson, R. D., and Lewis, B. G. 1990. DNA polymorphism in Leptosphaeria maculans. Physiol. Mol. Plant Pathol. 37:417-424.

17. Johnson, R. D., and Lewis, B. G. 1994. Variation in host range, systemic infection and epidemiology of Leptosphaeria maculans. Physiol. Mol. Plant Pathol. 43:269-277.

18. Koch, E., Song, K., Osborn, T. C., and Williams, P. H. 1991. Relationship between pathogenicity and phylogeny based on restriction fragment length polymorphism in Leptosphaeria maculans. Mol. Plant-Microbe Interact. 4:341-349.

19. Kousik, C. S., and Ritchie, D. F. 1996. Disease potential of pepper bacterial spot pathogen races that overcome the $B s 2$ gene for resistance. Phytopathology 86:1336-1343.

20. McNaughton, I. H. 1973. Synthesis and sterility of Raphanobrassica. Euphytica 22:70-88

21. Mengistu, A., Rimmer, S. R., Koch, E., and Williams, P. H. 1991. Patho- 
genicity grouping of isolates of Leptosphaeria maculans on Brassica napus cultivars and their disease reaction profiles on rapid-cycling Brassicas. Plant Dis. 75:1279-1282.

22. Morales, V. M., Pelcher, L. E., and Taylor, J. L. 1993. Comparison of the $5.8 \mathrm{~s}$ rDNA and internal transcribed spacer sequences of isolates of Leptosphaeria maculans from different pathogenicity groups. Curr. Genet. 23:490-495.

23. Morales, V. M., Séguin-Swartz, G., and Taylor, J. L. 1993. Chromosome size polymorphism in Leptosphaeria maculans. Phytopathology 83:503-509.

24. Pang, E. C. K., and Halloran, G. M. 1996. The genetics of adult-plant blackleg (Leptosphaeria maculans) resistance from Brassica juncea in B. napus. Theor. Appl. Genet. 92:382-387.

25. Parlevliet, J. E. 1993. What is durable resistance? A general outline. Pages 23-39 in: Durability of Disease Resistance. Th. Jacobs and J. E. Parlevliet, eds. Kluwer Academic Publishers, Dordrecht, the Netherlands.

26. Pederson, W. L., and Leath, S. 1988. Pyramiding major genes for resistance to maintain residual effects. Annu. Rev. Phytopathol. 26:369-378.

27. Petrie, G. A. 1969. Variability in Leptosphaeria maculans (Desm.) Ces. $\&$ de Not., the cause of blackleg of rape. Ph.D. dissertation. University of Saskatchewan, Saskatoon, Canada.

28. Petrie, G. A. 1978. Occurrence of a highly virulent strain of blackleg (Leptosphaeria maculans) on rape in Saskatchewan (1975-77). Can. Plant Dis. Surv. 53:26-28.

29. Petrie, G. A. 1986. Blackleg and other diseases of canola in Saskatchewan in 1984 and 1985. Can. Plant Dis. Surv. 66:51-53.

30. Rimmer, S. R., Searth, R., McVetly, P. B. E., Woods, D., Gugel, R., and Séguin-Swartz, G. 1995. Breeding for resistance to blackleg (stem canker) in western Canada. Blackleg News 5:11-15.

31. Rimmer, S. R., and Van den Berg, C. G. J. 1992. Resistance of oilseed Brassica spp. to blackleg caused by Leptosphaeria maculans. Can. J. Plant Pathol. 14:56-66.

32. Rouxel, T., Gall, C., and Balesdent, M. H. 1994. Du polymorphisme au complexe d'espèces: Combien d'agents pathogènes sont impliqués dans la nécrose du collet du colza? Agronomie 14:413-432.

33. Roy, N. N. 1978. A study on disease variation in the populations of an interspecific cross of Brassica juncea L. $\times$ Brassica napus L. Euphytica 27:145-149.

34. Roy, N. N. 1984. Interspecific transfer of Brassica juncea-type high blackleg resistance to Brassica napus. Euphytica 33:295-303.

35. Roy, N. N., and Reeves, J. 1975. Breeding better rape and linseed for western Australia. J. Agric. West. Aust. 16:93-97.

36. Sacristan, M. D., and Gerdemann, M. 1986. Different behavior of Brassica juncea and Brassica carinata as sources of Phoma lingam resistance in experiments of interspecific transfer to Brassica napus. Plant Breed. 97:304-314.

37. Salisbury, P. A., Ballinger, D. J., Wratten, N., Plummer, K. M., and Howlett, B. J. 1995. Blackleg disease on oilseed Brassica in Australia: A review. Aust. J. Exp. Agric. 35:665-672.

38. Scherrer, B. 1984. Biostatistique. G. Morin, ed. Boucherville, Québec, Canada.

39. Schramm, H., and Hoffmann, G. M. 1987. Infektionszeit Befallsentwicklung der Phoma-Wuzelhals-und Stengelfäule (Phoma lingam, Perfstadium Leptosphaeria maculans (Desm.) Ces. \& De Not.) an Winterraps, Auswirkungen von Fungizidbehandlungen. Gesunde Pflanz. 39:338-344.

40. Sippell, D. W., and Hall, R. 1995. Glucose phosphate isomerase polymorphisms distinguish weakly virulent from highly virulent strains of Leptosphaeria maculans. Can. J. Plant Pathol. 17:1-6.

41. Somda, I., Harkous, S., and Brun, H. 1997. Bipolar heterothallism in Bgroup isolates of Leptosphaeria maculans. Plant Pathol. 46:890-896.

42. Somda, I., Renard, M., and Brun, H. 1996. Morphology, pathogenicity and isozyme variation amongst French isolates of Leptosphaeria maculans recovered from Brassica juncea cv. Picra. Plant Pathol. 45:1090-1098.

43. Somda, I., Renard, M., and Brun, H. 1998. Seedling and adult plant reactions of Brassica napus-B. juncea recombinant lines towards A- and Bgroup isolates of Leptosphaeria maculans. Ann. Appl. Biol. 132:187-196.

44. Struss, D., Quiros, C. F., Plieske, J., and Röbbelen, G. 1996. Construction of Brassica B genome synteny based on chromosomes extracted from three different sources by phenotypic isozyme and molecular markers. Theor. Appl. Genet. 93:1026-1032.

45. Taylor, J. L., Borgmann, I. E., and Séguin-Swartz, G. 1991. Electrophoretic karyotyping of Leptosphaeria maculans differentiates highly virulent from weakly virulent isolates. Curr. Genet. 19:273-277.

46. Williams, P. H., and Delwiche, P. A. 1979. Screening for resistance to blackleg of crucifers in the seedling stage. Pages 164-170 in: Proc. Euc. Crucif. 1979 Conference. Van Marrewijk \& Toxopeus H., Wageningen, the Netherlands. 